\title{
Expertise in Decision-Making for Large Infrastructure Projects: From UK Trunk Roads to High Speed Rail 2
}

\author{
Geoffrey Dudley and David Banister, Transport Studies Unit, University of \\ Oxford
}

\begin{abstract}
At the decision-making stage a large-scale infrastructure project is essentially a broad concept, and this means the expert analyses will differ from each other and become contested over time, leading to the emergence of rival narratives. It is only where there is a limited range of expert analyses that the bases for decision-making will remain relatively clear-cut. Over time the contested nature of expertise can significantly inhibit the construction of effective narratives, either for or against the project, and also make decision-making more complex and problematic. Decision makers may also seek greater clarification through the construction of narratives that rise above these disputed areas of expertise, and the scientific evidence becomes less important. This paper examines the changing nature of contested expertise through a comparative analysis of political decision-making between UK trunk roads policy and the case of High Speed Rail 2, through the framework of epistemic communities.
\end{abstract}

Keywords: infrastructure; decision-making: high speed rail; epistemic communities; 


\section{Introduction}

Large infrastructure projects can absorb huge amounts of financial and material resources, yet little is understood about the dynamics of decision-making processes that sanction (or refuse) these projects. Given that specialist expertise of different kinds is an essential component in project analysis, assessment, and implementation, greater insights into its role can enhance our understanding of the means by which these decisions are made. It might be assumed that those holding relevant specialist expertises would play a key role in decision making processes, particularly with regard to large infrastructure projects, where engineering, technical, financial and economic, and operational expertise is essential for successful completion.

Nevertheless, specialist knowledge in itself cannot guarantee influence in decisionmaking, as different types of knowledge are required to break out of specialist niches (Geels and Kemp, 2012), and find the means to make an impact in both the public and the political arenas.

Haas defines an epistemic community as 'a network of professionals with recognised expertise and competence in a particular domain and an authoritative claim to policyrelevant knowledge within that domain or issue area' (Haas, 1992, p. 3). Haas claims that the members of an epistemic community share not only normative and causal beliefs, together with notions of validity, but also possess a common policy enterprise, i.e. a set of common practices associated with a set of problems to which their professional competence is directed, presumably out of the conviction that human welfare will be enhanced as a consequence (Haas, 1992, p. 3). The shared knowledge within an epistemic community, therefore, is not just knowledge acquired for its own sake, but is to be applied in order to solve problems in the real world. Opportunities to apply this knowledge are created through uncertainties among policy makers when confronted with fresh problems that require novel solutions (Dudley and Richardson, 1996, p. 68). Consequently, networks or communities of specialists that are capable of producing and providing the information emerge and proliferate (Haas, 1992, p. 4). It should also be stressed that, implicit in the epistemic communities concept, is the assumption that the expertise is of an authoritative character.

This policy relevant knowledge means that epistemic communities have at least the potential capacity to influence political decision makers at decisive moments. This capacity can also be enhanced significantly if they are able to capture public and political attention through such means as constructing coherent narratives that define the project, but crucially here there needs to be a common definition of the storyline. In this way, a successful narrative can have a vital role in establishing and fixing assumptions for decision-making under conditions of high uncertainty (Roe, 1994).

This paper builds on the notion of epistemic communities through a discussion of the means by which the Haas concept has been used in the decision-making process more generally, before taking two transport-related case studies to demonstrate the changing dynamics of road and rail infrastructure investment decisions. It is argued that the often contested nature of large-scale projects can lead to contradictory 
narratives, and that these divergent views can lead to a weakening of the role of expertise and the importance of 'scientific' evidence.

\section{Expertise: strengths and limitations}

At the decision-making stage a large-scale project offers a picture of the future, but it is unclear how it will be perceived and interpreted in public and political arenas. In this process, expertise must break out of its specialist niches, and paint a coherent picture that captures public and political attention and imagination (Fischer, 2009) - it needs to be more than a technical exercise. Yet the very size and complexity of the project can act as a major inhibitor of the influence exerted by epistemic communities, as there is a dilemma between maintaining simplicity and clarity in their expertise, and the need to accept the broader political and public agendas that also need to be satisfied. As Haas acknowledges, the range of impacts we might expect of epistemic communities is bounded by structural realities (Haas, 1992, p. 7). Consequently, where we find a proliferation and wide diversity of expertise, this can create conditions of contestation. In this environment, it can be extremely difficult for any area of expertise to establish its significance in the decision making process, and construct clear-cut narratives that carry a political impact. Contests can therefore emerge not only between those in favour or against the project, but also within an epistemic community itself, where such questions as the suitability and quality of methodologies can create major differences within a single area of expertise. In terms of the definition provided by Haas, the epistemic community will no longer possess a set of common practices associated with a set of problems, but there are clear divergences both within and between the different epistemic communities, over time and between the different projects.

Under these conditions of increasing contestation, that in turn creates congestion and complexity, the dynamics of expertise in large infrastructure projects can carry escalating and unpredictable impacts. For example, to illustrate the point about congestion, the introduction of new knowledge can produce fresh perspectives and interpretations, together with the formation of new epistemic communities. In this context, de Bruijn and Leijten observe that, under conditions of information overload, piles of reports will fail to provide the right information, and in the worst case trigger a call for even more information (de Bruijn and Leijten, 2007, p. 58). New knowledge can therefore produce a wide range of outcomes, including a growth in the diversity of specialist topics under debate; increases in the types and numbers of experts who gather around each cluster of specialist knowledge; and controversy over rival methodologies.

Ironically, as the arenas of expertise become more congested and contested, decision makers may seek greater clarification and simplicity through the construction of narratives that rise above, or even bypass, these disputed areas of expertise, so that the scientific evidence becomes less important. The wider political narratives define the project, and the epistemic communities are relegated to a subsidiary role in the decision-making process. As de Bruijn and Leijten comment, many decisions on large infrastructure projects have been insensitive to information (de Bruijn and Leijten, 2007, p. 50). In other words, as specialist knowledge becomes less important in decision-making, so greater emphasis is placed on constructing narratives that express values around which an effective political coalition can be formed. Sabatier promotes 
coalitions through the concept of advocacy that is composed of people from various organisations who share a set of normative and causal beliefs and who often work in concert (Sabatier, 1988, p. 133). Advocacy coalitions, like epistemic communities, are conceived not so much in terms of the core and periphery of a network, but as units which have the capacity to bridge policy arenas (Dudley and Richardson, 1996, p. 69). However, as the need to construct influential narratives would indicate, epistemic communities are likely to be most politically effective when they can translate their knowledge into values that can be widely understood and supported through an advocacy coalition.

Large infrastructure projects generally have a high political salience, and this characteristic highlights the relationship between specialist expertise and wider public and political values. In addition, although plans may be modified, ultimately there is a stark yes/no conclusion to the decision-making process that can heighten still further the political drama and salience. These tensions can be increased in the case of large transport infrastructure projects, for here their very nature entails high public use once the project is put into operation. In these cases, the public can view the project as one in which they have a personal stake, rather than of a type perceived in more impersonal community terms, such as in the water and energy industries. In turn, this personal connection and salience can place greater political pressure on decision makers to demonstrate values that encompass the wider benefits of the project over time. These pressures can be particularly acute where the project is publicly funded, for if it is to be paid for by taxpayers generally, then it is important to maximise the numbers of 'winners' over 'losers'.

However, given that the project is inevitably constrained spatially, assessing and demonstrating the wider benefits can carry a high degree of uncertainty, particularly if these benefits are to be estimated over space and time. In these cases, the problems of tackling the wider impacts can lead to the introduction of both new knowledge and relevant epistemic communities, but it is important to stress that it is an expertise of a different character to that more traditionally associated with large infrastructure projects.

With regard to these different types of expertise, firstly there are the more established areas of expertise associated with project implementation. These categories can include expertise that shows us how the project can be physically constructed, including planners, surveyors, and construction engineers; the expertise required to finance the project and (hopefully) control costs; and then the expertise required to operate the infrastructure once the project is completed. Secondly, on the other hand, there is a more conjectural type of expertise that can assess the wider, and more longterm, potential financial, economic, environmental and spatial impacts of the project, perhaps over a timescale covering several decades. Although there can be intense political pressure to produce clear and positive results from this latter type of expertise, the high degree of uncertainty and conjecture involved can result in disputes within epistemic communities over both outcomes and methodologies. In turn, the controversy and uncertainty can make it extremely difficult to construct coherent narratives from this kind of expertise, causing political decision makers to look elsewhere for inspiration. 
Given this uncertainty over the processes by which decision making takes place, this paper now looks in greater detail at two key examples of major investment in UK transport, to determine the role of expertise in the formation of epistemic communities, and the additional role that advocacy coalitions have had in the promotion of trunk roads and high speed rail 2 (HS2).

\section{Case studies}

\subsection{Background and history}

The comparative case studies of trunk roads and the case of HS2, illustrate the changing character and role of expertise in large infrastructure projects, and significant shifts in the relationship between knowledge and values. For example, these shifts are indicated in how the projects themselves are perceived politically, particularly with regard to the wide range of pressures and expectations to which a large-scale infrastructure project is subjected.

In the case of trunk roads, after many years in which the construction programme stalled, from the late 1950s the roads interests constructed a narrative for the value of road building that effectively captured the public and political imagination. It could be said, therefore, that the roads interests moved from being essentially a knowledgebased epistemic community to a more politically effective values based advocacy coalition. This coalition was dominant in the 1960s, and for much of the 1970s, but from the mid 1970s was increasingly challenged by a relatively loose environmental advocacy coalition. However, from the late 1980s the environmentalists placed much greater emphasis on acquiring scientific evidence to undermine the roads programme. When this evidence was combined with a skilful lobbying campaign in the 1990s, the outcome was a radical reduction in the trunk roads construction programme. In contrast to the roads interests, therefore, the environmentalists tended to move from an initial values based advocacy coalition, to the formation of more knowledge based epistemic communities. In both cases, however, at different times the rival interests could construct influential coalitions with clear-cut narratives.

In contrast, in the case of the modern HS2 (planned to connect the cities of London, Birmingham, Manchester, and Leeds), there is little evidence of the structure and coherence of the trunk roads case study. Instead, the nature and scale of the project appears to have precluded the construction of wide and politically effective advocacy coalitions, either for or against. In the case of epistemic communities, the sheer range and quantity of expertise employed has become much greater than for trunk roads, encompassing a complex and interconnecting variety of subjects (including environmental, social, economic and financial questions), and a diversity and fragmentation of views within each topic. The proliferation of topics means that it becomes more difficult for any one source of expertise to achieve a dominant political salience, and for clear narratives to be established that are effective over time. In addition, there is also the phenomenon of new knowledge bringing fresh perspectives and interpretations to the debate. However, this new knowledge can make the trajectory of the debate still more unpredictable, and create major splits in associated epistemic communities. In turn, there is recent evidence that leading advocates of HS2 are seeking narratives that have little connection to expert debates, and instead look to wider and more historic values in enlisting public support for the project. As 
Pellizzoni argues with regard to the relationship between expertise and politics, rather than an excessive technicisation of politics (i.e. political decision-making dominated by technical expertise), the issue seems now the opposite, namely the politicisation of science (Pellizzoni, 2011, p. 766). Nevertheless, in the case of HS2, we can take the evolution of the politicisation of science a stage further, so that political decision makers become disillusioned with scientific expertise, and find new sources for the construction of key narratives. For HS2, therefore, unlike trunk roads, there appears to be a disconnection between specialist knowledge and values in the decision-making process.

\subsection{The role of expertise}

With regard to HS2, it is not possible in this paper to cover all the wide range of topics covered by debate on the project. We will therefore focus on the two important specialist topics of Cost Benefit Analysis (CBA) and Wider Economic Impacts (WEIs). These two topics illustrate well how the introduction of new knowledge can lead to greater contestation over both results and basic methodologies, causing splits within the specialist epistemic communities. In turn, this makes the task of producing coherent narratives for HS2 much more difficult.

In the case of trunk roads, the material in this paper is based largely on extensive historical work in this area by Geoffrey Dudley and Jeremy Richardson (e.g. Dudley and Richardson, 1996, 1998, 2000). For HS2, given the co-author connection with the earlier work, the methods adopted are similar to those carried out in the trunk roads case study. For the purposes of this paper, they include detailed examination and analysis of the principal primary and secondary sources. In addition, therefore, to the relevant official and group publications, the secondary sources consulted include examination and analysis of all HS2 articles in the newspapers the Financial Times and The Guardian, from the beginning of 2008 until the present time, and examination and analysis over a similar time period for the practitioner journal Rail.

\subsubsection{UK trunk roads}

The case of UK trunk roads in the twentieth century offers a valuable example of how, at different times, both the roads interests, and later the opposing environmental lobby, were able to impose their knowledge and distinctive values on the policy process. They achieved this by constructing coherent and interconnected epistemic communities and wider advocacy coalitions, which effectively translated specialist knowledge into political narratives. It must be stressed that, although major policy change could happen quite quickly at times, on both sides of the divide the construction of successful coalitions, and the associated use of knowledge and narratives, took several decades (see Witting, 2013). This issue illustrates how policy processes, and the values underlying large transport infrastructure projects, evolve over time.

There was little success for the road builders in the early twentieth century. For example, a Road Board, set up in 1910, was wound up in 1920 with no major roads completed during its life (Dyos and Aldcroft, 1974, pp. 394-5). The one significant milestone came through the 1936 Trunk Roads Act, by which the Ministry of Transport took control over some 4500 miles of the most important through routes, 
which were now legally defined as 'trunk roads.' The fact that government now took direct responsibility for the principal roads at least offered hope that the subject would rise up the policy agenda, but again the road builders were to be disappointed. This was not for the want of ambitious plans by the epistemic community representing the roads interests themselves. For example, in 1938 the County Surveyors' Society produced a plan for a 1000 miles motorway network, and in 1946 this plan was largely adopted by the Labour government as one means of accelerating post war regeneration. The economic austerity of the 1940s and early 1950s, however, meant that government indifference soon returned, so that by the mid 1950s the roads interests were becoming desperate. It was at this point that they turned to a strategy of more overt political lobbying, and in 1955 the Roads Campaign Council was founded, with the express aim of gathering public support for road building. This change in strategy soon began to bear fruit, so that from 1955 the government finally began to seriously consider implementing the by now nearly two decades old County Surveyors' plan.

One of the reasons for this new enthusiasm was clearly the rising number of vehicles on the roads. For example, in 1945 the vehicles in use in Britain totalled 2.5 million, but by 1958 the number had more than trebled to almost 8 million (Plowden, 1973, p. 482). On its own, however, this does not explain the remarkable rise that took place in the fortunes of road building over the next few years. This depended on connecting the knowledge based epistemic community of the road builders, and the values based road lobby advocacy coalition, in the form of an irresistible political narrative that portrayed the new roads as essential for future national prosperity and well being.

Much of the credit for this process goes to a succession of Ministers of Transport, who not only made road building the predominant activity within the Ministry (Hamer, 1987, Dudley and Richardson, 2000), and so brought the epistemic community into the heart of policy making (the Ministry of Transport had executive authority over trunk roads under the $1936 \mathrm{Act}$ ), but also integrated implementation of the motorways programme into the powerful narrative of 'popular consumerism.' This potent narrative dominated UK transport policy for the next two decades, and carried the road building programme forward at an accelerating rate, so that by 1972 the Surveyors' plan for a 1000 miles network of motorways had been implemented. In these years, little opposition was encountered to any of the road schemes. Few people actually questioned the need for the road, but were merely concerned to shift it into someone else's back yard (Starkie, 1982, p. 131). Crucially, therefore, the heyday of motorway construction was before the era of significant protest, at least on questions of transport policy

From the early 1970s, however, this successful narrative was challenged by the emerging environmental lobby. Initially, the opposition occurred on a largely smallscale and ad hoc basis. In particular, disruptions took place at a number of public inquiries into controversial trunk roads schemes, and for the first time the actual need for the road was questioned (Tyme, 1978). Even though the environmentalists found it difficult to sustain their roads activity, by 1977 the government was sufficiently disillusioned with the roads 'popular consumerism' narrative to abandon the 'strategic network' approach, and instead adopt a more flexible policy. It was also a time of fiscal constraint (Cmnd. 6836, 1977). 
Despite its initial success, the environmental lobby had still to find a narrative that could capture public and political imagination over a long time period. In the event, it would be expert reports a decade or more later that would provide the trigger for new environmental narratives and processes of policy change. Ironically, these changes were initiated by an apparent revival for the roads interests. This came in the form of the 1989 White Paper Roads for Prosperity that committed the government to a doubling of the trunk roads construction programme (Cm 693, 1989). Even before government could embark on implementation of this programme, it became clear that it had badly under estimated the resulting backlash from the environmentalists.

Expert reports would play a major part in the construction of new narratives, and in this context a crucial turning point was the 1987 World Commission on Environment and Development, chaired by Gro Harlem Brundtland, which published the report Our Common Future (Brundtland, 1987). This report put forward the politically potent narrative of 'sustainable development,' defined as 'development that meets the needs of the present without compromising the ability of future generations to meet their own needs.' Sustainable development could be interpreted in many ways, but in the area of transport, where the concept quickly mutated into that of 'sustainable mobility' (see Banister, 2008), it offered a long-term narrative for the environmental advocacy coalition that could finally counter that of 'popular consumerism' for roads.

In the 1990s, the 'sustainable mobility' narrative was consolidated by a series of expert reports that put forward both alternative transport policies, and also undermined the case for a 'predict and provide' programme of road construction put forward in Roads for Prosperity. Firstly, in 1991 the Transport Studies Unit at the University of Oxford produced the Report Transport: The New Realism (Goodwin et al. 1991). The authors believed that a new realism was called for involving a policy mix that would include a substantial improvement in public transport, traffic calming, advanced traffic management systems, and road pricing (Goodwin et al, 1991, pp. 165-6). The Report won wide publicity (Dudley and Preston, 2013, p. 143) and as a type of apolitical forum acted as a pathfinder for the sustainable mobility narrative.

The second influential expert report was published in 1994 by the Royal Commission on Environmental Pollution (RCEP) on the subject of Transport and the Environment (Cm. 2674, 1994). The Commission was always chaired by a Fellow of the Royal Society, and tended to be viewed as a predominantly scientific body, although other disciplines, particularly law, economics, and philosophy, had always been represented (Owens and Rayner, 1999, p. 14). The Report set out clearly and methodically the dangers to public health posed by vehicle emissions, as well as examining the overall impact of transport policies. Most notably, the RCEP's recommendations included that planned expenditure on motorways and other trunk roads should be reduced to about half its then current level (Cm. 2674, 1994, para. 12.65). The RCEP therefore successfully linked scientific evidence on a serious threat to public health with the proposed growth of the road construction programme.

The third expert report was also published in 1994, by the Standing Advisory Committee on Trunk Road Assessment (SACTRA) on Trunk Roads and the Generation of Traffic. The principal conclusion of this report was that, based on the evidence it had studied, SACTRA believed that 'induced traffic can and does occur probably quite extensively, though its size and significance are likely to vary widely 
in different circumstances' (SACTRA, 1994, para. 15.03). For the purposes of the sustainable mobility narrative, this conclusion could be translated as 'new roads create traffic' that in environmental terms chimed well with the conclusions of the RCEP Report.

Each of the above expert reports achieved wide publicity, and the authoritative quality of the evidence was little challenged, even by the roads advocates. Just as in the 1960s and 1970s the strategy of linking road building to the narrative of popular consumerism won a policy hegemony for the roads interests, so in the 1990s the scientific evidence linked to the narrative of sustainable mobility was a powerful tool for the environmentalists in achieving their aim of undermining and destroying the Roads for Prosperity programme. In the event, the environmentalists constructed a coordinated multi arena campaign that combined public protest with the use of scientific evidence. For example, media publicity obtained through direct action occupation of road construction sites was employed to promote the findings of expert reports such as those produced by RCEP and SACTRA (Dudley, 2007). In a similar manner to the disruption of public inquiries in the 1970s, therefore, the direct action protests offered effective 'arenas without rules' (Dudley and Richardson, 1998) that allowed new knowledge and ideas to enter the policy debate.

By the late 1990s, the sustained campaign by the environmentalists was bearing fruit in terms of shifting the policy debate, so that from being perceived as a principal transport policy 'solution,' road building had now become a serious policy 'problem' for government. This process culminated in a 1998 Transport White Paper that acknowledged that the days of 'predict and provide' for roads were over, and that henceforth the emphasis would be on improving the maintenance and management of existing roads before building new ones (Cm. 3950, 1998, para. 3.123). This process of change was also assisted by the election of a Labour government in 1997 that was significantly more politically committed to introducing systems of integrated transport than its Conservative predecessor. Once again, therefore, widely acknowledged authoritative expertise had played a significant role in decision-making processes.

\subsubsection{High Speed 2 (HS2)}

In the case of HS2, a number of underlying factors have combined to make expertise arenas more contested, congested and complex. Ironically, some of the seeds for a more problematic role for expertise in large infrastructure projects were sown by the experience with trunk roads, such as public and political scepticism concerning the long-term value of these types of schemes, but other more modern factors include the role of new knowledge and ideas, and the wider and more politically intense expectations placed on large publicly funded projects (Albalate and Bel, 2014, p. 176).

The outcome is the need to have a strong vision of the purpose of the investment and its long-term impact on the transport system in the UK, and this requires the development of a narrative that captures both the public and political imagination. However, the construction of narratives becomes extremely difficult when there is a lack of both coherent and authoritative epistemic communities, and associated politically effective advocacy coalitions. Instead, HS2 decision making is characterised more by unpredictable and idiosyncratic processes, in which the 
contested and congested arenas of expertise have become largely disconnected from the values required to construct effective narratives over time, either for or against the project. Significantly, in contrast to the case of trunk roads, for HS2 there is not the equivalent of the relatively clear-cut split between the road and environmental epistemic communities and advocacy coalitions that, at different times, enabled each side to connect knowledge to narratives. Instead, there are a wide range of HS2 subjects under debate that can provoke unpredictable responses that cut across orthodox divisions of interests. It could also be said that, just as the heyday of motorway construction took place in a pre protest era, so the debate on HS2 takes place in a post protest era, in that much of the discussion occurs via the internet and social media. This may help to democratise the process, but also makes it more difficult for a single voice to make a significant impact.

In examining the underlying reasons for the changing status and dynamics of expertise, one basic factor that must be emphasised is that the sheer scale of the HS2 project, in physical, financial, and timescale terms, makes it inevitable that it is both intensely salient politically, and also susceptible to conditions of high uncertainty and controversy. In decision-making terms, HS2 was instigated by a Labour government in 2009 (DfT, 2009, Cm 7827, 2010) and carried forward by the subsequent coalition government, so that in 2012 the Department for Transport (DfT) announced the decision to proceed with the Y-shaped rail network linking London, the West Midlands and the North of England (Cm 8247, 2012). There are important contrasts with roads here in that, regardless of the size of a single motorway scheme, it was always conceived in terms of being a component part of a national network, whereas HS2 has generally been perceived as a single entity (although we will see below that there are now greater official efforts to construct a narrative for HS2 in network terms). The scale of the project is also indicated by the indicative budget, which in 2013 was increased for construction of the network to $£ 42.6$ billion (including a contingency of $£ 14.4 \mathrm{bn}$.), plus $£ 7.5 \mathrm{bn}$. for rolling stock, making a total of just over $£ 50$ bn. (in 2015 this projected cost was increased to $£ 55.6 \mathrm{bn}$.). The long timescale is indicated in that phase one, from London to Birmingham, is due to open in 2026, with phase 2a, to Crewe, in 2027, and then phase 2 b, to Leeds and Manchester, due to open in 2033. At the moment, it is intended that the whole project will be publicly funded.

There are major challenges for expertise in the size and timescale of HS2, particularly with regard to the projected budget. As the large contingency demonstrates, the cost of the project is subject to a high degree of uncertainty, and this has placed strains on the cross-party consensus that has backed the project. The salience of the budgetary process for HS2 has also been heightened by systematic international comparisons that demonstrate the apparently endemic tendency for large infrastructure projects to significantly exceed their projected budgets (e.g. Flyvbjerg et al, 2003; Flyvbjerg, 2007; De Jong et al, 2013). In turn, these splits within one epistemic community can have escalating effects that place greater political pressures on other knowledge based communities.

Consequently, the scale of HS2, together with contested expertise over its budget costs, can accentuate political pressures for the project to demonstrate its long-term value to the taxpayer, and to maximise the number of 'winners' over 'losers.' The outcomes of these pressures can be the introduction of new knowledge, and also 
epistemic communities to assess and calculate the wider economic impacts (WEIs) of HS2. These bring into play factors that exist well beyond the direct operational impacts, including the promotion of economic growth and regeneration, the reduction of regional wealth inequalities (see Tomaney and Marques, 2013), and the attainment of environmental goals such as a reduction in carbon emissions. However, the high degree of conjecture and uncertainty surrounding these types of impacts can provoke further splits in the relevant epistemic communities concerning not only outcomes, but also basic methodologies.

New knowledge and ideas can also shift perceptions that underpin established epistemic communities and methodologies. For example, significantly greater emphasis is now placed on gaining insights into the dynamics of human behaviour (Dudley and Preston, 2013), such as the value placed on savings in travel time, particularly given developments in mobile technologies. As Banister argues, the overriding concern with time savings needs to be balanced with a richer interpretation of the many different constructs of time that might begin to increase our understanding of travel decisions, the quality of time, and the benefits of slower not faster movement (Banister, 2011, p. 957). This has particular relevance for HS2 in that, initially, significant time savings was given as a principal motivation for the construction of HS2 (e.g. Cm 7827, 2010, pp. 13-15), but subsequently the value to be ascribed to time savings has become the subject of expert debate, given the ability of the modern traveller to work on the train with the use of mobile technologies. Debate over cost benefit analyses (CBAs) is far from new, but the impact of new knowledge, such as questioning the basic value of savings in travel time, can have the more fundamental effect of undermining CBA as a methodology.

In the case of CBA for HS2, on one level unpredictable exogenous factors can cause significant changes. For example, Department for Transport (DfT) figures indicate that between February 2011 and October 2013, the benefit cost ratio (BCR) for the full network (Phases 1 and 2) without the inclusion of WEIs, fell from 2.2:1 to 1.8:1, particularly as a result of revised assumptions about economic growth and rail demand (HC 851, 2013, paras. 19-20). The sharp downward revision of these figures, over a relatively short period of time, indicates how the volatility of economic conditions and forecasts can have major impacts on the credibility of large infrastructure projects such as HS2, and bring into doubt the suitability of BCRs as a guide to decision making, and its suitability is further questioned when new knowledge causes reinterpretations and consequent reassessments. In the case of HS2, this is evident in the value placed on savings in travel time. As we noted above, developments in mobile technologies have caused major reassessments concerning the value in CBA terms of time-savings. Consequently, after considerable expert pressure, the DfT was eventually persuaded to reduce the value of time-savings by one third in the case of business travel (although this reduction was somewhat offset by a projected increase in the numbers of business travellers) (HC 851, 2013, para. 22). Given that time-savings had previously been one of the central pillars for the HS2 CBA, this introduction of new knowledge undermined markedly the economic case for HS2. (see HL 134, 2015). It should also be noted that the HS2 element represents only one component of a journey. It is the average speed door-to-door (not the maximum speed) and ease (or inconvenience) of transfer between modes of transport that is central (Banister and Givoni, 2014). This perspective of door-to-door travel 
places HS2 in the context of transport networks, rather than the single entity that has generally defined the narrative.

Significantly, the DfT did not change its approach to CBA as a result of the work of an acknowledged expert forum, as we saw in the case of trunk roads, but rather in response to an accumulation of expert evidence over time. The outcome was therefore a further undermining of the credibility of CBA. This is reflected in splits within epistemic communities concerning the basic value of CBA. For example, Helm argues that marginal analysis, which lies at the heart of CBA, has little to offer in the case of deciding how much infrastructure to provide. Instead, with regard to HS2, he believes that the question is whether to have a high speed rail system, within which this particular section would fit. This means that the costs and benefits of the system as a whole need to be taken into account first, and in this context it is essential to place HS2 in a wider historical context, and to understand its ability to change the economy as a whole over time (Helm, 2013, p. 290). It is notable that this type of fundamental criticism of CBA as a methodology for assessing projects such as HS2 has permeated to the level of political decision-making. For example, in September 2013 Secretary of State for Transport Patrick McLoughlin described CBA as a narrow estimate on a narrow range of factors (Financial Times, 12:09:13). It could be said that McLoughlin's criticisms of CBA reflected government political embarrassment concerning the significant reduction in the cost benefit ratio for HS2, but in wider terms it indicated how a lack of consensus on even the basic methodologies used to assess the value of the project has undermined the credibility and authority of the relevant epistemic communities.

The undermining of the value in travel time savings has caused the government to place greater emphasis both on the value of HS2 in providing greater network capacity, and also its wider economic benefits in providing investment and jobs (e.g. DfT, 2013). However, particularly in the case of WEIs, there are again fundamental splits in epistemic communities that undermine the credibility of new knowledge and basic methodologies. For example, in 2013 the consultants KPMG were commissioned by HS2 Ltd (the public body given executive authority for the project by the DfT) to develop a methodological framework designed to analyse the potential scale, range, and distribution of regional economic impacts associated with the substantial improvements to the rail network brought about by HS2, and the use of freed-up capacity on the classic network. KPMG acknowledged the innovative nature of this work and the methodologies, and stressed that the analysis focused on the potential impact of investment in HS2 on the structure of regional economies in the longer term, and that this made it different from conventional approaches to the appraisal of transport schemes, which are based on the estimation of the monetary value of travel (HS2 Ltd, 2013, p. 7). Nevertheless, KPMG estimated that investment in HS2 could potentially generate $£ 15$ billion a year in productivity gains for the GB economy in 2037 (at 2013 prices), and that this would represent an increase of around 0.8 per cent in the total level of GDP (HS2 Ltd, 2013, p. 13).

There were clearly political pressures to ascribe positive WEIs for HS2, but the apparently high figure of $£ 15$ billion, together with the methodology employed to achieve it, attracted widespread criticism from other experts in the field. For example, Professor Henry Overman of the London School of Economics, and a former advisor to HS2, claimed that KPMG used a procedure that was 'essentially made up' (HC 
788, 2013, Q99) while Dan Graham, Professor of Statistical Modelling at Imperial College London, argued that the statistical work by KPMG was not reliable (HC 788, 2013, Q97). In this context, it is significant that the DfT has subsequently commissioned a team of experts to undertake a comprehensive study of the mechanisms through which transport investment affects economic performance, and the extent to which these are captured in the current appraisal methodology (HM Government, 2014, para. 2.3.16, Venables et al, 2014, DfT 2014). On this occasion the aim was to heal a basic split within a knowledge based epistemic community, rather than between values based adversarial advocacy coalitions that was more common in the case of trunk roads. Underlying these splits, however, there were the political pressures placed on an epistemic community to devise and deliver results in a policy area that inevitably carried a high degree of uncertainty.

The internal strains placed on epistemic communities by HS2 severely inhibited the potential of expert knowledge to influence decision making processes. Instead, the onus for the construction of politically influential narratives was thrown on to innovative interests and individuals seeking to find the HS2 equivalent to 'popular consumerism' and 'sustainable mobility' for trunk roads. The most notable example of the construction of this type of values based narrative is provided by HS2 Chairman Sir David Higgins, who in 2014 produced a Report HS2 Plus that set out his proposals for the project (HS2 Ltd, 2014a). At the heart of this Report was the narrative of HS2 as fulfilling an historic national need. It therefore relied little on the work of epistemic communities such as that seen for CBA and the WEIs, but instead placed HS2 in the context of the successor infrastructure to the original railway network constructed by the Victorians in the nineteenth century, and later the motorway network of the twentieth century. He concluded that, if done right, HS2 can provide an answer that stands the test of time, and addresses the issues of congestion in the South and the lack of connectivity in the North. On the other hand, without HS2, the people of the country will continue to face the failures of the transport system on a daily basis (HS2 Ltd, 2014a, p. 18). It should be noted that, in stressing the place of HS2 within a total network, Higgins was echoing the perspective proposed above by Helm. This network approach therefore suggested one means whereby expert knowledge might be reconnected to the values underlying political narratives.

\section{Implications for decision making in large infrastructure projects}

The main conclusion from this paper is that, under conditions of increasing contestation, congestion, and complexity, the status and significance of expertise on major transport infrastructure projects diminishes over time. In the case of HS2, at the heart of this decline lie the increasingly intense and unrealistic expectations that have been placed on expertise to justify the essentially political decisions to proceed with a particular project. In contrast, in the case of trunk roads the role of expertise in decision-making was basically to assist in the construction of politically effective narratives. By the time of HS2, however, there is the paradox that, as new knowledge enters the policy arenas, and both the range of subjects under review and the numbers of experts increases, so their capacity to make a significant contribution to decisionmaking processes is greatly reduced. This paradox is explained by the fact that publicly funded projects such as HS2 are so large and politically salient that it becomes imperative for governments to both justify the expenditure, and to maximise 
the numbers of 'winners' from its construction. In doing so, it places demands on expertise to deliver results in areas with extremely high degrees of uncertainty and complexity. Once it becomes clear that expertise cannot provide the desired outcomes in these areas, evident in such phenomena as major splits within epistemic communities, then political decision makers become disillusioned with this type of specialist expertise, and they turn their attentions elsewhere for support and inspiration towards more intangible values stressing historical national need. As Pellizzoni observes, science becomes overabundant, resulting in controversial decisions that cannot be legitimated. The search for certainty produces greater uncertainty (Pellizzoni, 2011, 768).

A way forward therefore needs to be a greater public recognition of both the inevitably large political element in the decision making process, and the limitations of expertise in providing definitive evidence to justify a particular decision. For example, in the case of HS2, greater openness and public transparency in decisionmaking could be reflected in more official attention being given to a strategic vision for UK transport policy that covers all modes of transport, and examines the links between land use and transport development more widely. Within this vision, the role for rail transport should be clearly identified, including within that the role for high speed rail (see Van Wee, 2007). It is significant that at least the beginnings of such a debate appear now to be taking place, particularly with regard to the place of HS2 within regional transport and economic strategies (eg. 1North, 2014; Mayor of London, 2014; HS2 Ltd., 2014b, National Infrastructure Commission, 2016). In this context, there now appears to be significant concern generally about the apparent limitations of CBA to accurately appraise the impacts over time of large infrastructure projects. As we have seen, CBA has been fundamental to project appraisal since the 1960s, but the major disputes within epistemic communities concerning both CBA outcomes and methodologies suggests a decline in its political significance that may be difficult to reverse.

In the context of the potential political influence of expertise, the role of strong narratives in decision-making processes could also be more openly recognised. As we saw in the case of trunk roads, the construction of narratives need not preclude the integration of authoritative expertise, and they can be powerful tools in winning public and political attention. For example, as we noted above, placing HS2 within the wider context of total transport networks offers one means of reconnecting knowledge to values. At the same time, greater public openness could also be reflected in the reduction of political pressure on specialist expertise to produce definitive results in policy areas of inevitably high uncertainty and complexity. Instead, acknowledgment of the essentially political nature of many long term large-scale infrastructure projects could assist in the political reconnection of knowledge and values by reducing the range of subjects under study, and giving greater weight to authoritative expertise in the appropriate policy areas. As Martens and Van Weelden conclude, the evidence on decision-making for transport infrastructure suggests that the emphasis should shift from the exploration and design of ideal types, towards the analysis and assessment of the efficacy of various coping strategies (Martens and Van Weelden, 2014, p. 664).

In these processes of reconnecting knowledge and values, one other crucial factor to take into consideration is that of the long timescale for large infrastructure projects, in both their construction and their impacts. In this sense, there is a provisional element 
to every decision. For example, in the case of HS2 there needs to be more explicit consideration given to monitoring the project during its construction, to cover cost control and the capacity that is needed. Essentially, this means that systems need to be flexible and adaptable to new external factors and other decisions taken within the economy. A greater recognition of the conditional and provisional nature of knowledge in large infrastructure projects would therefore acknowledge its strengths and limitations in decision-making processes.

\section{Acknowledgments}

This paper forms part of the project: 'The Politics of Decision Making in Large Infrastructure Projects: The Case of High Speed Rail 2' funded by the Rees Jeffreys Road Fund. We would like to thank David Bonilla, Phil Goodwin, Peter Jones, Jeremy Richardson, and Antje Witting for their valuable comments on earlier drafts of this paper.

\section{References}

Albalate, D. and Bel, G. (2014) The Economics and Politics of High-Speed Rail, Lexington Books, Plymouth.

Banister, D. (2008) 'The Sustainable Mobility Paradigm,' Transport Policy, 15, (2), pp. $73-80$

Banister, D. (2011) 'The Trilogy of Distance, Speed and Time,' Journal of Transport Geography, 19, (4), pp. 950-959.

Banister, D. and Givoni, M. (2014) The Economic Case for HS2, TSU Working Paper Series, Ref. 1066. School of Geography and the Environment, Oxford.

Brundtland, G.H. (1987) Our Common Future. The Report of the World Commission on Environment and Development, Oxford University Press, Oxford.

Cm. 693 (1989) Roads for Prosperity, HMSO, London.

Cm. 2674 (1994) Royal Commission on Environmental Pollution, Eighteenth Report, Transport and the Environment, HMSO, London.

Cm. 3950 (1998) A New Deal for Transport: Better for Everyone. The Government's White Paper on the Future of Transport, SO, London.

Cm. 7827 (2010) High Speed Rail, SO, London.

Cm. 8247 (2012) High Speed Rail: Investing in Britain's Future - Decisions and Next Steps, SO, London.

Cmnd. 6836 (1977) Transport Policy, HMSO, London.

De Bruijn, H. and Leijten, M. (2007) 'Megaprojects and Contested Information,' Transportation Planning and Technology, 30, (1), pp. 49-69. 
De Jong, M., Annema, J.A., and Van Wee, G.P. (2013) 'How to Build Major Transport Infrastructure Projects Within Budget, In Time and with the Expected Output; A Literature Review,' Transport Reviews, 33,( 2), pp. 195-218.

DfT (2009) Britain’s Transport Infrastructure. High Speed Two. DfT, London .

DfT (2014) Transport Investment and Economic Performance: Peer Reviews, DfT, London.

Dudley, G. (2007) 'Individuals and the Dynamics of Policy Learning: The Case of the Third Battle of Newbury,’ Public Administration, 85, (2), pp. 405-28.

Dudley, G. and Preston, J. (2013) 'Historical Narrative and the Evolution of Academic Transport Studies in the United Kingdom,' Transport Reviews, 33, (2), pp. 131-147.

Dudley, G. and Richardson, J. (1996) 'Why Does Policy Change Over Time: Adversarial Policy Communities, Alternative Policy Arenas, and British Trunk Roads Policy 1945-95,' Journal of European Public Policy, 3, (1), pp. 63-83.

Dudley, G. and Richardson, J. (1998) 'Arenas Without Rules and the Policy Change Process: Outsider Groups and British Roads Policy,' Political Studies, 46, (4), pp. 727-47.

Dudley, G. and Richardson, J. (2000) Why Does Policy Change? British Transport Policy 1945-99, Routledge, London.

Dyos, H.J. and Aldcroft, D.H. (1974) British Transport. An Economic Survey from the Seventeenth Century to the Twentieth, Pelican, London.

Fischer, F. (2009) Democracy and Expertise: Reorienting Public Inquiry, Oxford University Press, Oxford.

Flyvbjerg, B. (2007) 'Policy and Planning for Large-Infrastructure Projects:

Problems, Causes, Cures,' Environment and Planning B: Planning and Design, 34, (4), pp. 578-97.

Flyvbjerg, B., Skamrisholm, M.K. and Buhl, S.L. (2003) 'How Common and How Large are Cost Overruns in Transport Infrastructure Projects,' Transport Reviews, 23, (1), pp. 71-88.

Geels, F.W. and Kemp, R. (2012) 'The Multi-Level Perspective as a New Perspective for Studying Socio-Technical Transitions,' in Geels, F.W., Kemp, R., Dudley, G. and Lyons, G. (Eds.) Automobility in Transition? A Socio-Technical Analysis of Sustainable Transport, Routledge, New York, pp. 49-79.

Goodwin, P., Hallett, S., Kenny, F., and Stokes, G. (1991) Transport: The New Realism, Rees Jeffreys Road Fund, London. 
Haas, P.M. (1992) 'Introduction. Epistemic Communities and International Policy Co-ordination,’ International Organisation, 46, (1), pp. 12-35.

Hamer, M. (1987) Wheels Within Wheels. A Study of the Road Lobby, Routledge and Kegan Paul, London.

HC 788 (2013) Oral Evidence: Economics of HS2, House of Commons Treasury Select Committee, 05:11:13, SO, London.

HC 851 (2013) High Speed Rail: On Track? House of Commons Transport Committee, Ninth Report of Session 2013-14, SO, London

Helm, D. (2013) 'British Infrastructure Policy and the Gradual Return of the State,' Oxford Review of Economic Policy, 29, (2), pp. 287-306.

HL 134 (2015) House of Lords Economic Affairs Committee, $1^{\text {st }}$ Report of Session 2014-15, The Economics of High Speed 2, SO, London

HM Government (2014) Getting Set for HS2: Responding to the HS2 Growth Taskforce, HM Government, London.

HS2 Ltd. (2013) HS2 Regional Economic Impacts, (Report prepared by KPMG) HS2, London.

HS2 Ltd. (2014a) HS2 Plus. A Report by David Higgins, HS2, London

HS2 Ltd. (2014b) Rebalancing Britain: From HS2 Towards a National Transport Strategy, HS2, London.

Martens, K. and Van Weelden, P. (2014) 'Decision-Making on Transport Infrastructure and Contested Information: A Critical Analysis of Three Approaches,' European Planning Studies, 22, (3), pp. 648-66.

Mayor of London (2014) London Infrastructure Plan 2050: Transport Supporting Paper, TfL, London.

National Infrastructure Commission (2016) High Speed North.

1North (2014) One North. A Proposition for an Interconnected North, 1North.

Owens, S. and Rayner, T. (1999) 'When Knowledge Matters: The Role and Influence of the Royal Commission on Environmental Pollution,' Journal of Environmental Policy and Planning, 1, (1), 7-24.

Pellizzoni, L. (2011) 'The Politics of Facts: Local Environmental Conflicts and Expertise,' Environmental Politics, 20, (6), pp. 765-785.

Plowden, W. (1973) The Motor Car and Politics in Britain, Pelican, London. 
Roe, E. (1994) Narrative Policy Analysis: Theory and Practice, Duke University Press, Durham, NC.

Sabatier, P.A. (1988) 'An Advocacy Coalition Framework of Policy Change and the Role of Policy-Oriented Learning Therein,' Policy Sciences, 21, (2), pp. 129-68.

SACTRA (1994) Trunk Roads and the Generation of Traffic, HMSO, London.

Starkie, D. (1982) The Motorway Age. Road and Traffic Policies in Post-War Britain, Pergamon Press, Oxford.

Tomaney, J. and Marques, P. (2013) 'Evidence, Policy, and the Politics of Regional Development: The Case of High-Speed Rail in the United Kingdom,' Environment and Planning C: Government and Policy, 31, (3), pp. 414-27.

Tyme, J. (1978) Motorways Versus Democracy, Macmillan, London.

Van Wee, B. (2007) 'Rail Infrastructure: Challenges for Cost-Benefit Analysis and Other ex ante Evaluations,' Transportation Planning and Technology, 30, (1), pp. 3148.

Venables, A.J., Laird, J., and Overman, H. (2014) Transport Investment and Economic Performance: Implications for Project Appraisal, Department for Transport, London.

Witting, A. (2013) The Role of Knowledge in Policy Development: Towards a DeCarbonised British Road Transport Infrastructure, PhD Thesis, University of Constance. 